EXTENDED REPORT

\title{
Simvastatin reduces MMP-3 level in interleukin $1 \beta$ stimulated human chondrocyte culture
}

\author{
P E Lazzerini, P L Capecchi, F Nerucci, A Fioravanti, F Chellini, M Piccini, S Bisogno, R Marcolongo, \\ F Laghi Pasini
}

Ann Rheum Dis 2004;63:867-869. doi: 10.1136/ard.2003.009746

See end of article for authors' affiliations

.....................

Correspondence to: Dr F Laghi Pasini, Department of Clinical Medicine and

Immunological Sciences, Division of Clinical Immunology, University of

Siena, Policlinico "Le Scotte" ${ }^{\prime \prime}, 53100$ Siena, Italy; laghi@unisi.it

Accepted

5 September 2003

\begin{abstract}
Objectives: Matrix metalloproteinases (MMPs) produced by chondrocytes play a role in the development of cartilage degradation in joint diseases. Moreover, inhibition of MMP secretion by macrophages accumulating in arteriosclerotic plaques would account for the plaque stabilising activity of statins in cardiovascular patients. Recently, simvastatin has been shown to inhibit both developing and established collagen induced arthritis in a murine model. We thus decided to investigate the effect of simvastatin on the production of MMP-3 from cultured interleukin (IL) 1 stimulated human chondrocytes.

Methods: Cells from human cartilage, obtained from eight subjects with osteoarthritis undergoing surgery for total hip prostheses, were cultured in the presence of different concentrations of simvastatin 15,10 , and $50 \mu \mathrm{mol} / \mathrm{l}$ ) with and without IL1 $\beta$ (5 ng/ml). MMP-3 level was measured in the culture medium after $48 \mathrm{~h}$ of incubation.

Results: IL1 $\beta$ stimulation of chondrocytes increased MMP-3 concentration in the cultures (from 0.69 (0.09) to $1.94(0.12) \mathrm{ng} / \mu \mathrm{g}$ protein). Incubation with simvastatin was associated with a dose dependent reduction in MMP-3 increase, both in the presence $(-15 \%,-17 \%$, and $-26 \%$ with 5,10 , and $50 \mu \mathrm{mol} / \mathrm{I}$, respectively) and in the absence (-32\% with $50 \mu \mathrm{mol} / \mathrm{I})$ of ILI $\beta$. The inhibiting effect of simvastatin was completely reversed by the addition of mevalonate $(100 \mu \mathrm{mol} / \mathrm{l})$ or farnesol $(10 \mu \mathrm{mol} / \mathrm{l})$.

Conclusions: Our data show that simvastatin, by blocking HMGCoA-reductase and interfering in the prenylation processes, is able to inhibit MMP-3 production from cultured human chondrocytes that have been either unstimulated or stimulated with ILI $\beta$, thus suggesting a possible additional mechanism for statins in counteracting chronic joint disease related cartilage damage.
\end{abstract}

$\mathrm{S}$ everal studies have provided evidence for a significant role of matrix metalloproteinases (MMPs), particularly MMP-3 or stromelysin-1, produced by chondrocytes, in the development of cartilage degradation in joint diseases. ${ }^{12}$ MMP release by chondrocytes may be enhanced in conditions of physical and chemical stress. Among the mediators of tissue injury in the course of ostheoarthritis and inflammatory joint diseases, one cytokine, interleukin (IL) l, is actively involved in the development and progression of cartilage damage by different mechanisms, including enhancement of MMP production. ${ }^{34}$

HMG-CoA reductase inhibitors (statins) are able to reduce mortality in cardiovascular diseases by means of hypolipidaemic and non-hypolipidaemic pharmacological effects. The latter include a stabilising activity on the arteriosclerotic plaque, possibly by increasing collagen content in the fibrous cap. This effect is referred to as the statin dependent inhibition of MMP secretion by macrophages accumulating in the plaque. ${ }^{5}$ Macrophages are capable of degrading extracellular matrix by phagocytosis or by secretion of proteolytic enzymes that may weaken the fibrous cap, predisposing to its rupture ${ }^{6}$ and to secondary thrombosis and embolisation. Furthermore, recent data suggest that the effect of statins on MMPs is dependent on the inhibition of mevalonate synthesis and, as a consequence, the production of mevalonate isoprenoid derivatives, such as farnesyl pyrophosphate and geranylgeranyl pyrophosphate. These molecules, by modifying specific intracellular proteins by covalent attachment during the so-called prenylation process, play an essential role in the regulation of several cellular mechanisms, including cytoskeletal dynamics and endocytotic/exocytotic transport, which are involved in MMP secretion. ${ }^{7}$ Moreover, a recent paper showed that simvastatin markedly inhibited not only developing but also established collagen induced arthritis in a murine model. ${ }^{8}$

Based on the above observations, we tested the possibility that the statin dependent inhibition of MMP production could also be reproduced in a different cell model such as human chondrocytes. Thus, the effect of increasing concentrations of simvastatin on the production of MMP-3 from cultured human chondrocytes stimulated with ILl $\beta$ was studied. In addition, proteoglycan (PG) production was also measured in order to rule out a possible unfavourable inhibitory effect of simvastatin on the biosynthetic activity of chondrocytes.

\section{MATERIALS AND METHODS Chondrocyte culture}

Human cartilage was obtained from the femoral heads of eight subjects with osteoarthritis undergoing surgery for total hip prostheses (5M, 3F; mean (SD) age 63.7 (10.1) years). Cartilage was cut aseptically and minced into $2 \mathrm{~mm}^{2}$ pieces. The cartilage fragments were then digested by clostridial collagenase (Sigma, St Louis, MO, USA) $1 \mathrm{mg} / \mathrm{ml}$ in PBS. Collagenase digestion was carried out at $37^{\circ} \mathrm{C}$ for $14-18 \mathrm{~h}$ with moderate stirring.

Cells obtained after digestion were cultured in 24 well microplates at a density of $3 \times 10^{5}$ cells/well and overlaid with $1 \mathrm{ml}$ of medium containing $10 \%$ fetal calf serum, $200 \mathrm{U} / \mathrm{ml}$ penicillin, $200 \mu \mathrm{g} / \mathrm{ml}$ streptomycin, $2 \mathrm{mmol} / \mathrm{l}$ glutamine, and $50 \mu \mathrm{g} / \mathrm{ml}$ ascorbate in Dulbecco's minimum essential

Abbreviations: MMP, matrix metalloproteinase; PG, proteoglycan 
medium. Cells were maintained in an atmosphere of $5 \% \mathrm{CO}_{2}$ in air at $37^{\circ} \mathrm{C}$ for 48 hours.

\section{Study with simvastatin}

The effect of simvastatin $+/-$ ILl $\beta$ was analysed on chondrocytes cultured as described above.

Cells were grown in culture medium with $5 \mathrm{ng} / \mathrm{ml}$ human recombinant ILl $\beta$ (Boehringer Mannheim, Germany) and simvastatin $(5,10$, and $50 \mu \mathrm{mol} / \mathrm{l}$; Merck \& Co Inc, Rahway, NJ, USA). Cells were also cultured in the presence of $50 \mu \mathrm{mol} / \mathrm{l}$ simvastatin alone. A control sample of chondrocytes cultured in the absence of simvastatin and ILI $\beta$ was also evaluated in all experiments. Finally, the effect of the addition of exogenous mevalonate $(100 \mu \mathrm{mol} / \mathrm{l})$, farnesol ( $10 \mathrm{~mol} / \mathrm{l})$, and geranylgeraniol $(10 \mathrm{mmol} / \mathrm{l})$ (all Sigma) was evaluated in the $50 \mu \mathrm{mol} / \mathrm{l}$ simvastatin samples, with or without ILl $\beta$.

After $48 \mathrm{~h}$ the medium was removed, and stored at $-70^{\circ} \mathrm{C}$ pending determination of its MMP-3 content. Cell viability was evaluated by Trypan blue and methylthiazoletetrazolium (MTT) (both Sigma).

\section{MMP-3 assays}

The amount of total MMP-3 in the culture medium was measured by an immunoenzymatic method on microplates (Biotrak Matrix MMP-3 ELISA System, Amersham,

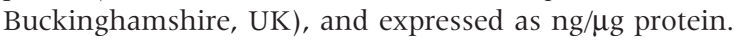

\section{Proteoglycan assays}

The amount of PG in the culture medium was evaluated by a solid phase enzyme amplified sensitivity immunoassay (Biosource PG EASIA kit, BioSource Europe SA, Belgium) performed in a microtitre plate, and expressed as $\mu \mathrm{g} / \mathrm{ml}$. Cells from three of the eight patients with osteoarthritis were studied in duplicate. In this part or the study, the concentration of simvastatin employed was $50 \mu \mathrm{mol} / \mathrm{l}$.

\section{Statistical analysis}

Results were statistically evaluated by Student's $t$ test for paired data. Values of $\mathrm{p}<0.05$ were considered significant.

\section{RESULTS}

IL1 $\beta$ stimulation of chondrocytes was able to increase MMP3 production (from $0.69(0.09)$ to $1.94(0.12) \mathrm{ng} / \mu \mathrm{g}$ protein). Incubation with simvastatin was associated with a dose dependent significant reduction of MMP-3 production, both in the presence $(-15 \%,-17 \%$, and $-26 \%$ with 5,10 , and $50 \mu \mathrm{mol} / \mathrm{l}$, respectively) and absence $(-32 \%$ with $50 \mu \mathrm{mol} / \mathrm{l})$ of IL1 $\beta$ (fig l-2). In the $50 \mu \mathrm{mol} / \mathrm{l}$ samples, with or without ILl $\beta$, the inhibiting effect of simvastatin was completely reversed by the addition of mevalonate $(100 \mu \mathrm{mol} / \mathrm{l})$ and farnesol $(10 \mu \mathrm{mol} / \mathrm{l})$ (fig $1-2)$. In contrast, no reversal effect was observed when the culture was co-incubated with geranylgeraniol $(10 \mu \mathrm{mol} / \mathrm{l})$ (fig. $1-2)$.

The addition of simvastatin $50 \mu \mathrm{mol} / \mathrm{l}$ did not significantly affect proteoglycan synthesis from ILl $\beta$ treated and untreated cell cultures. Levels of proteoglycans were 2.38 (0.86) $v 3.10(1.04) \mu \mathrm{g} / \mathrm{ml}$, and 1.31 (0.48) $v 1.69(0.77) \mu \mathrm{g} /$ $\mathrm{ml}$ for control sample $v$ control $+50 \mu \mathrm{mol} / \mathrm{l}$ simvastatin, and control + I Ll $\beta v$ control + ILl $\beta+50 \mu \mathrm{mol} / \mathrm{l}$ simvastatin, respectively.

Viability of the cells was maintained, as demonstrated by the evaluation with Trypan blue, which indicated 90-95\% viability with simvastatin $50 \mu \mathrm{mol} / \mathrm{l}$. Longer term preservation of cell viability was confirmed with MTT (88-92\%) in the same conditions.

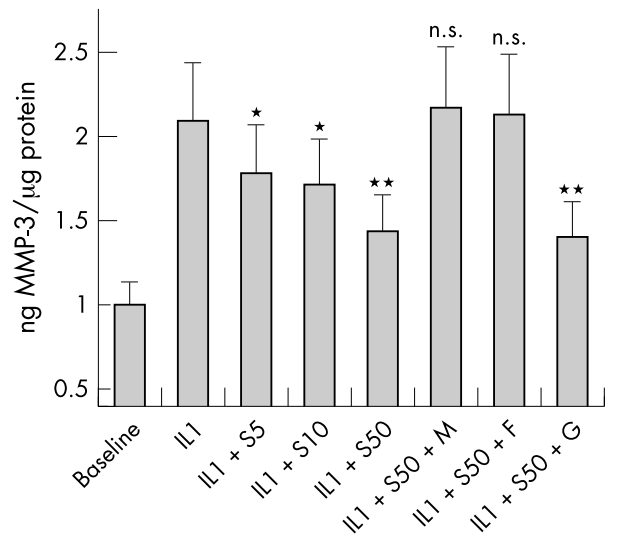

Figure 1 Effect of the $48 \mathrm{~h}$ incubation with 5, 10, and $50 \mu \mathrm{mol} / \mathrm{l}$ simvastatin (S) and $50 \mu \mathrm{mol} / \mathrm{I} \mathrm{S}+100 \mu \mathrm{mol} / \mathrm{I}$ mevalonate (M), $50 \mu \mathrm{mol} /$ I simvastatin $+10 \mu \mathrm{mol} / \mathrm{I}$ farnesol (F), and $50 \mu \mathrm{mol} / \mathrm{I}$ simvastatin + $10 \mu \mathrm{mol} / \mathrm{I}$ geranylgeraniol (G) on $5 \mathrm{ng} / \mathrm{ml} \mathrm{IL1} \beta$ dependent MMP-3 production (expressed as $\mathrm{ng} / \mu \mathrm{g}$ protein) from cultured chondrocytes from osteoarthitis patients. All experiments were performed in duplicate. Data are expressed as mean (SD). Baseline sample represents the blank control. Student's $t$ test for paired data (simvastatin treated samples + ILI $\beta v$ untreated sample + ILI $\beta$ ). " $p<0.05 ;{ }^{* *} p<0.01 ; n=8$.

\section{DISCUSSION}

Recent evidence has shown that statins possess a variety of biological properties, other than lipid lowering abilities, including immunomodulating and anti-inflammatory effects. In particular, these agents have been shown to inhibit the production of cytokines such as MCP- $1,{ }^{9}{ }^{10}$ IL $8,{ }^{10}$ and IL6; $;{ }^{11}$ to block LFA-1 mediated adhesion and co-stimulation of lymphocytes; ${ }^{12}$ and to reduce the expression of MHC-II molecules, thus interfering with $\mathrm{T}$ cell activities. ${ }^{13}$ Interestingly, a very recent work showed that simvastatin markedly inhibited not only developing but also established collagen induced arthritis in a murine model. Ex vivo analysis demonstrated a significant suppression of collagen specific Thl humoral and cellular immune responses and a reduction of anti-CD3/anti-CD28 proliferation and IFN- $\gamma$ release from mononuclear cells derived from peripheral blood and synovial fluid. ${ }^{8}$ Thus, statins may reasonably play a role in chronic inflammatory conditions, such as rheumatic diseases. ${ }^{14}$ Moreover, recent studies have demonstrated that

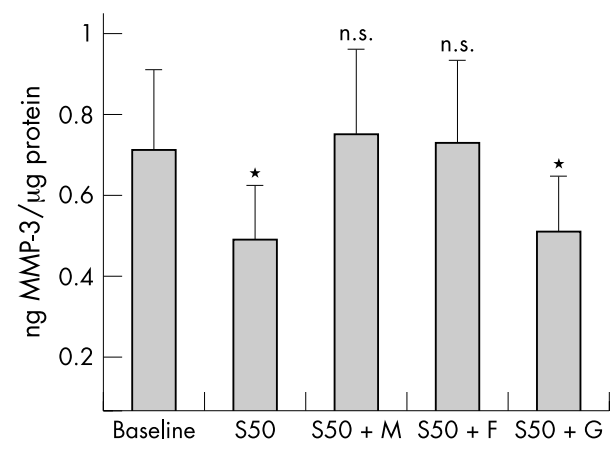

Figure 2 Effect of the $48 \mathrm{~h}$ incubation with $50 \mathrm{mmol} / \mathrm{I}$ simvastatin (S), $50 \mu \mathrm{mol} / / \mathrm{l}$ simvastatin $+100 \mu \mathrm{mol} / \mathrm{I}$ mevalonate (M), $50 \mu \mathrm{mol} / \mathrm{I}$ simvastatin $+10 \mu \mathrm{mol} / \mathrm{l}$ farnesol (F), and $50 \mu \mathrm{mol} / \mathrm{I}$ simvastatin + $10 \mu \mathrm{mol} / \mathrm{I}$ geranylgeraniol (G) on spontaneous MMP-3 production (expressed as $\mathrm{ng} / \mu \mathrm{g}$ protein) from cultured chondrocytes from osteoarthitis patients. All experiments were performed in duplicate. Data are expressed as mean (SD). Student's $t$ test for paired data (simvastatin treated samples $v$ untreated sample). ${ }^{*} \mathrm{p}<0.05 ; \mathrm{n}=8$. 
some statins inhibit MMP production both in vitro ${ }^{5}$ and in vivo. ${ }^{16}{ }^{17}$ This effect of statins provides further evidence for a possible additive cartilage protective mechanism of action of these agents in joint diseases.

Our data show that simvastatin is able to inhibit MMP-3 production from cultured human chondrocytes stimulated with ILl $\beta$, and from unstimulated cells. The complete prevention of the inhibitory effect of the drug seen after coincubation with mevalonate suggests that simvastatin influences chondrocyte MMP-3 production through its blocking activity on HMGCoA reductase, a key enzyme in the cholesterol biosynthetic pathway, which synthesises the isoprenoid precursor mevalonate. In the same way, the pivotal role of prenylated, and more particularly farnesylated proteins, in the process leading to MMP-3 production is further confirmed by the peculiar ability of farnesol (but not geranylgeraniol) to completely revert the effect of simvastatin. Bellosta et $a l^{5}$ demonstrated that statins reduce MMP-9 production by cultured macrophages without any interference in MMP-9 gene expression or in the activation process after the secretion of the protease. Moreover, a recent study reported that statins are able to inhibit the production of other MMPs, including MMP-3, in different cell lines without producing any change in MMP mRNA levels. ${ }^{15}$ Based on these data, and because the covalent addition of isoprenoids to proteins (the prenylation process) plays an important role in regulating membrane traffic, it seems conceivable that statin interference in isoprenoid synthesis may lead to a reduced MMP-3 secretion by chondrocytes.

It seems remarkable that this potential anti-resorptive effect of simvastatin is not associated with a concomitant inhibition of chondrocyte biosynthetic activity; as a result, the overall activity of simvastatin on cartilage metabolism should produce favourable effects. In fact, proteoglycan synthesis was not significantly modified by simvastatin in our study. Indeed, simvastatin seems to produce a slight increase in proteoglycan concentration in the medium from chondrocyte cultures, also partially reversing the well known ILl induced proteoglycan downregulation. ${ }^{18}$ This effect was not statistically significant, which may be due to the fact that the sample size was small. A study of the effects of simvastatin on proteoglycan metabolism was beyond the scope of the present paper; nevertheless, the possibility that simvastatin may increase proteoglycans in resting and stimulated chondrocytes deserves further studies, which are now in progress.

These novel findings would suggest that statins may play a protective role in rheumatic diseases by acting on either the basic immunological mediators, or the final effectors of tissue damage. Our results, although very preliminary, may help further our understanding of the possible therapeutic role of statins in the prevention of irreversible cartilage damage associated with ostheoarthritis and inflammatory joint diseases. More studies are now in progress in order to give further insight into the mechanism of action of these drugs.

\section{ACKNOWLEDGEMENT}

We gratefully acknowledge Merck Research Laboratories, Merck \& Co Inc, Rahway, NJ, USA for kindly providing us with simvastatin.

\section{Authors' affiliations}

P E Lazzerini, P L Capecchi, F Laghi Pasini, Department of Clinical Medicine and Immunological Sciences, Division of Clinical Immunology University of Siena, Siena, Italy

F Nerucci, A Fioravanti, F Chellini, M Piccini, S Bisogno, R Marcolongo,

Division of Rheumatology, University of Siena, Siena, Italy

\section{REFERENCES}

1 Taylor DJ, Cheung NT, Dawes PT. Increased serum proMMP-3 in inflammatory arthritides: a potential indicator of synovial inflammatory monokine activity. Ann Rheum Dis 1994;53:768-72.

2 Lohmander LS, Hoerrner LA, Lark MW. Metalloproteinases, tissue inhibitor, and proteoglycan fragments in knee synovial fluid in human oateoarthritis. Arthritis Rheum 1993;36:181-9.

3 van den Berg WB. The role of cytokines and growth factors in cartilage destruction in osteoathritis and rheumatoid arthritis. Z Rheumatol 1999:58:136-41.

4 Stove J, Huch K, Gunther KP, Scharf HP. Interleukin-1 $\beta$ induces different gene expression of stromelysin, aggrecan and tumor-necrosis-factor-stimulated gene 6 in human osteoarthritic chondrocytes in vivo. Pathobiology 2000;68:144-9.

5 Bellosta S, Via D, Canavesi M, Pfister P, Fumagalli R, Paoletti R, Bernini R. HMG-CoA reductase inhibitors reduce MMP-9 secretion by macrophages. Arterioscler Thromb Vasc Biol 1998;18:1671-8.

6 Dollery CM, McEwan JR, Henney AM. Matrix metalloproteinases and cardiovascular disease. Circ Res 1995:77:863-8.

7 Corsini A, Bellosta S, Baetta R, Fumagalli R, Paletti R, Bernini R. New insight into the pharmacodynamic and pharmacokinetic properties of statins. Pharmacol Ther 1999;84:413-28.

8 Leung BP, Sattar N, Crilly A, Prach M, McCarey DW, Payne H, et al. A novel anti-inflammatory role for simvastatin in inflammatory arthritis. J Immunol 2003; 170:1524-30

9 Romano M, Diomede L, Sironi M, Massimiliano L, Sottocorno M, Polentarutti $N$, et al. Inhibition of chemiotactic protein-1 synthesis by statins. Lab Invest 2000:80:1095-1100.

10 Kothe H, Dalhoff K, Rupp J, Muller A, Kreuzer J, Maass M, et al. Hydroxymethylglutaryl coenzyme A reductase inhibithors modify the inflammation response of human macrophages and endothelial cells infected with Chlamydia pneumoniae. Circulation 2000;101:1760-3.

11 Musial J, Undas A, Gajewski P, Jankowski M, Sydor W, Szczeklik A. Antiinflammatory effects of simvastatin in subjects with hypercholesterolemia. Int J Cardiol $2001 ; 77: 247-53$.

12 Weitz-Schmidt G, Welzenbach K, Brinkmann V, Kamata T, Kallen J, Bruns C, et al. Statins selectively inhibit leukocyte function antigen-1 by binding to a novel regulatory integrin site. Nat Med 2001;7:687-92.

13 Kwak B, Mulhaupt F, Myit S, Mach F. Statins as a newly recognized type of immunomodulator. Nat Med 2000;6:1399-402.

14 Palinski W. Immunomodulation: a new role for statins? Nat Med 2000;6:1311-12.

15 Luan Z, Chase AJ, Newby AC. Statins inhibit secretion of metalloproteinases$1,-2,-3$, and -9 from vascular smooth muscle cells and macrophages. Arterioscler Thromb Vasc Biol 2003;23:769-75.

16 Crisby M, Nordin-Fredriksson G, Shah PK, Yana J, Zhu J, Nilsson J. Pravastatin treatment increases collagen content and decreases lipid content, inflammation, matrix metalloproteinases and cell death in human carotid plaques: implications for plaque stabilization. Circulation 2001;103:926-33.

17 Fukumoto Y, Libby P, Rabkin E, Hill CC, Enomoto M, Hirouchi Y, et al. Statins alter smooth muscle cell accumulation and collagen content in established atheroma of Watanabe heritable hyperlipidemic rabbits. Circulation 2001;103:993-9.

18 Stove J, Huch K, Gunther KP, Scharf HP. Interleukin-1 beta induces different gene expression of stromelysin, aggrecan and tumor-necrosis-factorstimulated gene 6 in human osteoarthritic chondrocytes in vitro. Pathobiology 2000;68:144-9. 